\title{
The Course and Impact of Poststroke Insomnia in Stroke Survivors Aged 18 to 65 Years: Results from the Psychosocial Outcomes In StrokE (POISE) Study
}

\author{
Nick Glozier ${ }^{\mathrm{a}}$ Tom J. Moullaali ${ }^{\mathrm{b}} \quad$ Børge Sivertsen ${ }^{\mathrm{c}-\mathrm{e}} \quad$ Dukyeon Kim $^{\mathrm{a}}$ \\ Gillian Mead $^{g}$ Stephen Jan ${ }^{b}$ Qiang Li ${ }^{b}$ Maree L. Hackett ${ }^{a}$ b, $f$ \\ a Brain and Mind Centre, The University of Sydney, Sydney, NSW, Australia; \\ b The George Institute for Global Health, The University of Sydney, Sydney, NSW, Australia; \\ 'Department of Public Mental Health, Norwegian Institute of Public Health, Bergen, Norway; \\ ${ }^{d}$ The Regional Centre for Child and Youth Mental Health and Child Welfare, Uni Research \\ Health, Bergen, Norway; ${ }^{e}$ Department of Psychiatry, Helse Fonna HF, Haugesund, Norway;

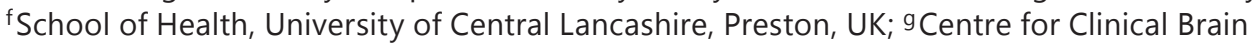 \\ Sciences, University of Edinburgh, Edinburgh, UK
}

Keywords

Stroke $\cdot$ Insomnia $\cdot$ Disability $\cdot$ Work $\cdot$ Depression $\cdot$ Anxiety $\cdot$ Cohort

\begin{abstract}
Background: Insomnia symptoms are common in the population and have negative psychosocial and functional sequelae. There are no prospective studies of the course of such symptoms and their impact, if any, in stroke survivors. This prospective cohort study investigated insomnia after stroke in working-age adults and evaluated its impact on psychological and functional outcomes over the subsequent year. Methods: We prospectively recruited 441 young ( $<65$ years) consecutive stroke survivors from 20 public hospitals in the New South Wales Stroke Service network. Participants were assessed by self-report and interview at 28 days, 6 months, and 12 months after stroke. Insomnia was defined using a common epidemiological measure of sleep disturbance and daytime consequences. Depression, anxiety, disability, and return to work were assessed through standardized measures. Results: The point prevalence of insomnia at each time point in the year after stroke was stable at $30-37 \%$ and more common in females. Fifty-eight (16\%) of all participants reported "chronic" insomnia, with symptoms at both baseline and 6 months later. At 12 months, this group was more likely to be depressed (OR 6.75, 95\% CI 2.78-16.4), anxious (OR 3.31, 95\% CI 1.54-7.09), disabled (OR 3.60,95\% CI 2.07-6.25), and not have returned to work, compared to those without
\end{abstract}


Glozier et al.: The Course and Impact of Poststroke Insomnia in Stroke Survivors Aged 18 to 65 Years: Results from the Psychosocial Outcomes In StrokE (POISE) Study

insomnia over the same period. Conclusions: Chronic insomnia has a negative effect on disability and return to work 1 year after stroke even after adjusting for demographic, psychiatric, and disability factors. Identifying and appropriately targeting insomnia through known effective treatments may improve functional outcomes after stroke.

(C) 2017 The Author(s)

Published by S. Karger AG, Basel

\section{Introduction}

Insomnia, classically defined as the presence of difficulties getting to, and maintaining, sleep most nights over a period of time, with daytime consequences [1], is reported to affect between $12 \%$ [2] and 37\% [3] of stroke survivors, with higher rates of individual symptoms without daytime consequences [2-6]. Poststroke insomnia with daytime consequences is associated with depression [2-4], diabetes [2], disability [3], and fatigue [3]. Frequent awakening, but no other insomnia symptoms, is associated with suicidal ideation [5]. There are only 3 previous studies (4 publications [2-5]) with a total of 1,154 participants, assessing insomnia after stroke, none of which were prospective. There are no data to guide patients, families, or clinicians about the course of insomnia or its impact, compared to the number of intensive studies investigating the links between sleep symptoms and stroke lesion sites [6], or poststroke fatigue.

Given reported links between insomnia and greater disability, health service use, and even mortality in working-age adults [7-10], poststroke insomnia may have significant and deleterious effects. Younger (working-age) stroke survivors have lower mortality than older survivors [11], and high (up to $75 \%$ ) return-to-work rates [12,13]. Insomnia symptoms in younger stroke survivors therefore have the potential for substantial detrimental effects on personal health and well-being, in addition to wider economic costs of disability and unemployment.

\section{Aims and Hypotheses}

We investigated the pattern of insomnia after stroke, and whether the course over the first 6 months is associated with depression and anxiety symptoms, disability, and return to work in the first year after stroke.

\section{Methods}

\section{Participants}

The Psychosocial Outcomes In StrokE (POISE) study was a prospective observational cohort study, recruiting consecutive participants from 20 public hospitals in the Stroke Services New South Wales clinical network in Australia between 2008 and 2010 with the aim of evaluating the course and outcome of psychosocial characteristics after stroke in workingage people [14]. Sleep disturbance was a preplanned secondary analysis, although the widespread geography of the sample prevented clinical interviews for insomnia.

Participants were eligible if they were between 18 and 65 years of age, had had a recent stroke (within 28 days), spoke English sufficiently well to respond to study questions, and they or their proxy could give informed written consent. Participants with receptive aphasia, severe language disorder, or cognitive impairment were eligible to participate if their proxy 
provided consent and completed assessments on their behalf. Only $16(4.4 \%)$ were interviewed through proxy in the first month, $13(3.5 \%)$ at 6 months, and $15(4.1 \%)$ at 12 months. POISE was registered with the Australian New Zealand Clinical Trials Registry number ANZCTRN 12608000459325. A detailed description of the study methods and instruments can be found elsewhere [14].

\section{Procedures}

Baseline sociodemographic, medical, and clinical characteristics of participants were recorded by hospital-based research nurses. All participants were then interviewed face to face or, if impractical, over the phone, by trained interviewers at 1, 6, and 12 months after stroke.

\section{Insomnia}

Insomnia was ascertained using 3 items from the Karolinska Sleep Questionnaire (KSQ). The KSQ has previously shown excellent psychometric properties [15], and these 3 items have been validated against a clinical diagnosis of insomnia [16], using the International Classification of Sleep Disorders criteria [1]. The following items, rated on a 5-point scale, were used, each specifically adapted to be used for poststroke participants: (1) "Since your stroke, have you had any problems getting to sleep?", (2) "Since your stroke, how often have you woken too early and not been able to get back to sleep?", and (3) "Since your stroke, how often have you been tired or sleepy at work or during your spare time?" asked at 1 month poststroke. At subsequent assessments, the time frame was specified as the past 4 weeks. Participants were categorized as having insomnia if they reported problems with either of the 2 nocturnal symptoms (sleep onset insomnia and/or early morning awakening insomnia) more frequently than "often/several times per week," in addition to reporting daytime consequences of tiredness or sleepiness more frequently than "often/several times per week." These 3 items were used to create an "insomnia course" variable: (1) "chronic insomnia": insomnia symptoms were reported at 28 days and 6 months after stroke, (2) "early insomnia": symptoms present at 28 days but not at 6 months, (3) "late insomnia": symptoms first reported at 6 months, and (4) "no insomnia": no symptoms reported either at 28 days or 6 months. No information was available on middle-of-the-night awakenings/sleep maintenance insomnia, which according to the Research Diagnostic Criteria [17] would be required to fulfil the criteria for insomnia syndrome. The confounding presence of snoring and stopping breathing at night (indicative of sleep apnoea) was also determined using the KSQ questions.

Symptoms of anxiety and depression were measured using the self-report Hospital Anxiety and Depression Scale (HADS) [18]. The HADS is validated in hospital settings and primary care [19]. A cutoff score of $\geq 8$ for each subscale of depression and anxiety best balances sensitivity and specificity ( 0.80 for depression according to DSM-III and IV, ICD-8 and 9 criteria). In the current study, the HADS scores were dichotomized using this cut point to indicate a "case" of either depression or anxiety. Disability was assessed using the World Health Organization Disability Assessment Schedule II (WHODASII) [20], validated in stroke populations [21]. Alcohol consumption was evaluated with the Alcohol Use Disorders Identification Test (AUDIT-C) [22], where a score of $\geq 8$ indicates hazardous drinking. Cognitive status was determined using the Telephone Interview for Cognitive Status (TICS), a score of $<21$ indicating cognitive impairment [23]. Information on paid work was collected using questions from the Australian Bureau of Statistics 2006 Census [24]. Psychosocial barriers to return to work were determined using the Job Content Questionnaire [25]. High job stress was defined as those jobs with high demands (e.g., long hours) and low control (e.g., limited or no choice concerning what work was completed). Economic factors included health and income protection insurance. 
Glozier et al.: The Course and Impact of Poststroke Insomnia in Stroke Survivors Aged 18 to 65 Years: Results from the Psychosocial Outcomes In StrokE (POISE) Study

\section{Statistical Analysis}

Analyses were performed using SAS version 9.3 (SAS institute, Cary, NC, USA). The data used for the main analyses consisted of participants with complete sleep data at all 3 time points. The baseline characteristics of these participants were compared to those lost to follow-up, or who provided incomplete sleep data. There was no imputation of missing data. The point prevalence at baseline, 6 , and 12 months, and the pattern of insomnia over these 2 assessments was estimated. This insomnia course over the first 6 months was used as the "exposure" in the models and defined as above. The associations of insomnia with demographic, health, and functioning variables in the first month after stroke were estimated using odds ratios (OR). Logistic regression models were used to determine the association of the insomnia course over 6 months, with depression, anxiety, and return-to-work status at 12 months. Ordinal logistic regression was used to determine the association of insomnia with disability. For the purposes of this study, the right skewed WHODASII score was categorized into quartiles (with observed cut points at 2.2, 8.2, and 19.6) at 12 months. Models were adjusted for (i) age and sex, and (ii) significant psychiatric and functional confounding variables from univariate analyses. Data are reported with OR and 95\% confidence intervals (CI). These models were adjusted for age (continuous) and sex, and sequentially adjusted for the presence of baseline psychological variables such as depression/anxiety, and psychotropic use, other comorbidities, and disability in the first few weeks after stroke.

Ethical approval was received from the Human Research Ethics Committee of the Sydney South West Health Service in May 2008, protocol X08-0084.

\section{Results}

Over the study period, 618 potential participants were screened, 441 consented, and 414 were interviewed at baseline ( 27 were misdiagnosed on file review, withdrew consent, were too ill, or died). Of those not participating, 40 declined, 30 spoke insufficient English, 36 were too ill or died before assessment, and the others were ineligible for study reason, e.g., overseas visitors. Of the study population, $46(11 \%)$ were lost to follow-up, died, withdrew consent later, or provided incomplete sleep data, leaving 368 (84\%) participants providing data for these analyses over the subsequent year. The $11 \%$ not included were less likely to have financially dependent children ( 20 vs. $36 \%, p=0.03$ ), less likely to be in paid work (35 vs. $21 \%$, $p=0.04$ ), and reported greater disability (mean WHODASII score 38.3 vs. $24.9, p=0.0005$ ) but did not differ in any other way at baseline. The majority $(306 / 368,83 \%)$ had an ischaemic stroke, with $46(13 \%)$ having a haemorrhagic stroke and 11 having other types according to OCPSC criteria.

The Prevalence and Course of Poststroke Insomnia Symptoms over 6 Months

The prevalence of significant insomnia symptoms was stable (30-37\%) ateach assessment point in the year poststroke, although these were not the exact same participants each time. Over the first 6 months, the prevalence of chronic insomnia was (16\%), indicating that of the 124 with insomnia in the month after stroke, 58 (47\%) had insomnia at 6 months, whilst 66 (53\%) recovered. Of the 244 (66\%) participants without insomnia at baseline, 192 (77\%) remained good sleepers, whilst 52 (23\%) developed insomnia by 6 months (Fig. 1).

\section{Health, Function, and Psychosocial Factors Associated with Insomnia during the First Month after Stroke}

Table 1 outlines the participant characteristics associated with insomnia in the first month after stroke. Insomnia was associated with female sex, depressive and anxiety 


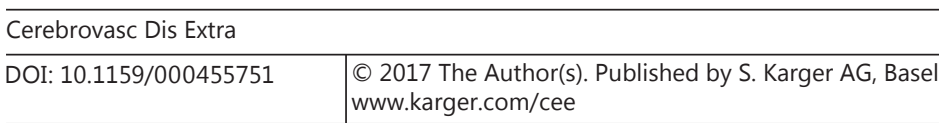

Glozier et al.: The Course and Impact of Poststroke Insomnia in Stroke Survivors Aged 18 to 65 Years: Results from the Psychosocial Outcomes In StrokE (POISE) Study

Fig. 1. The course of insomnia over 1 year following stroke. Text in bold indicates 6-month insomnia descriptive patterns used to assess 12-month outcomes. Data are displayed as $n(\%)$.

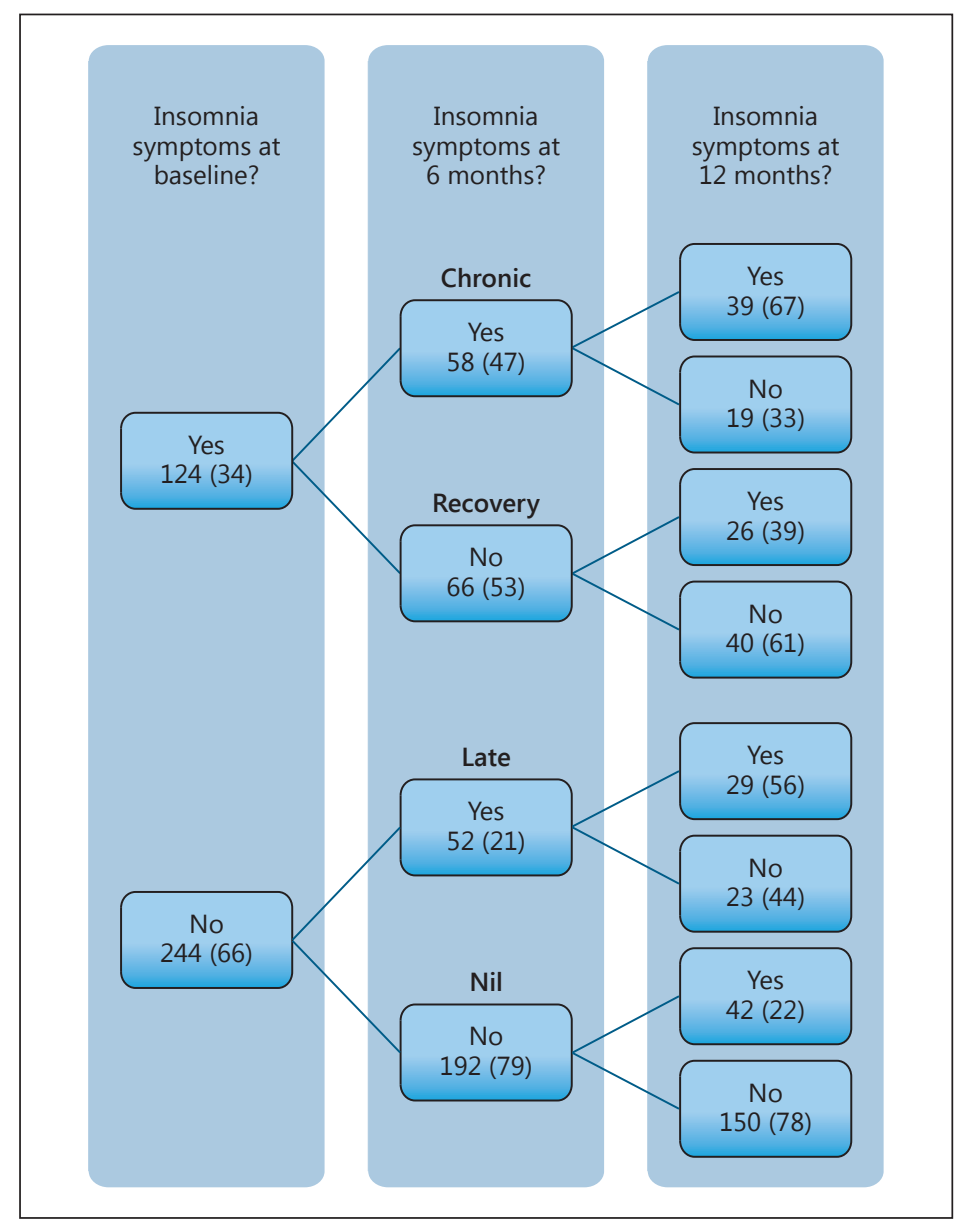

symptoms, and prestroke psychotropic medication use or counselling. There were higher levels of disability in those with insomnia (mean score 31.2 [SD 21.4]) than those without (21.7 [SD 19.4]). Insomnia was not associated with comorbid illness, excessive alcohol, cognitive dysfunction, or a range of psychosocial and financial pressures such as having financially dependent children or being the main income earner at baseline.

\section{Association of the Course of Insomnia over 6 Months with Psychological and Functional}

Outcomes at 12 Months

Depression and Anxiety. The associations of 6-month insomnia patterns with 12-month outcomes are shown in Table 2. In sex- and age-matched models, compared to the non-insomniacs, those with "chronic" insomnia were more likely to be depressed (OR 6.75, 95\% CI 2.7816.4) and anxious (OR 3.31, 95\% CI 1.54-7.09) at 12 months. The same was also true for those who had recovered from insomnia, although the associations were weaker (depression OR 2.78, 95\% CI 1.06-7.30; anxiety OR 2.94, 95\% CI 1.41-6.14). The late-onset insomnia group also had higher rates of anxiety (OR 2.65, 95\% CI 1.17-6.00) at 12 months. The association with depression was of a similar magnitude but nonsignificant (OR 2.48, 95\% CI 0.84-7.27). In each case, the associations were attenuated after further adjustment for psychiatric treatment before stroke and anxiety/depressive symptoms in the month after stroke (Table 2 , model 2). A similar pattern was seen when examining the association of insomnia course with continuous measures of depressive and anxious symptoms (data not shown). 
Glozier et al.: The Course and Impact of Poststroke Insomnia in Stroke Survivors Aged 18 to 65 Years: Results from the Psychosocial Outcomes In StrokE (POISE) Study

Table 1. Association of insomnia in the first month after stroke with baseline participant characteristics

\begin{tabular}{|c|c|c|c|c|}
\hline & $\begin{array}{l}\text { Insomnia } \\
\left(n=124^{*}\right)\end{array}$ & $\begin{array}{l}\text { No insomnia } \\
\left(n=244^{*}\right)\end{array}$ & OR $(95 \%$ CI) & $p$ value \\
\hline \multicolumn{5}{|l|}{ Sociodemographic } \\
\hline \\
\hline $46-65$ years & $87(70)$ & $192(79)$ & ref. & \\
\hline $18-45$ years & $37(30)$ & $52(21)$ & $1.57(0.96-2.57)$ & 0.07 \\
\hline \multicolumn{5}{|l|}{ Sex } \\
\hline Male & $71(57)$ & $180(74)$ & ref. & \\
\hline Female & $53(43)$ & $64(26)$ & $2.10(1.33-3.31)$ & 0.001 \\
\hline \multicolumn{5}{|l|}{ Education } \\
\hline Up to age 16 & $46(37)$ & $86 / 243(35)$ & ref. & \\
\hline Age 18 /trade & $27(22)$ & $70 / 243(29)$ & $0.72(0.41-1.28)$ & 0.26 \\
\hline Diploma/degree & $51(41)$ & $87 / 243(36)$ & $1.10(0.67-1.80)$ & 0.72 \\
\hline \multicolumn{5}{|l|}{ Marital status } \\
\hline Married/de facto & $83(67)$ & $154(63)$ & ref. & \\
\hline Never married & $23(19)$ & $60(25)$ & $0.71(0.41-1.23)$ & 0.22 \\
\hline Other & $18(15)$ & $30(12)$ & $1.11(0.59-2.12)$ & 0.74 \\
\hline \multicolumn{5}{|l|}{ Living alone } \\
\hline Yes & $17(14)$ & $44(18)$ & ref. & \\
\hline No & $107(86)$ & $200(82)$ & $1.38(0.75-2.54)$ & 0.29 \\
\hline \multicolumn{5}{|l|}{ Employment } \\
\hline Paid full-time & $67(54)$ & $132(54)$ & ref. & \\
\hline Paid part-time & $15(12)$ & $33(14)$ & $0.90(0.45-1.76)$ & 0.75 \\
\hline Retired & $8(6)$ & $34(14)$ & $0.46(0.20-1.06)$ & 0.07 \\
\hline Unemployed & $34(27)$ & $45(18)$ & $1.49(0.87-2.54)$ & 0.14 \\
\hline \multicolumn{5}{|l|}{ Nonmanual occupation } \\
\hline No & $50 / 114(44)$ & $118 / 228(52)$ & ref. & \\
\hline Yes & $64 / 114(56)$ & $110 / 228(48)$ & $1.37(0.87-2.16)$ & 0.17 \\
\hline \multicolumn{5}{|l|}{ Job strain } \\
\hline Others (active, passive) & $82(66)$ & $165(68)$ & ref. & \\
\hline High demands/low control & $25(20)$ & $31(13)$ & $1.62(0.90-2.93)$ & 0.11 \\
\hline Low demands/high control & $17(14)$ & $48(20)$ & $0.71(0.39-1.32)$ & 0.28 \\
\hline \multicolumn{5}{|l|}{ Financially dependent children } \\
\hline No & $73(59)$ & $163 / 243(67)$ & ref. & \\
\hline Yes & $51(41)$ & $80 / 243(33)$ & $1.42(0.91-2.23)$ & 0.12 \\
\hline \multicolumn{5}{|l|}{ Main income earner } \\
\hline Yes & 68/122 (56) & $154 / 241(64)$ & ref. & \\
\hline No & $54 / 122(44)$ & $87 / 241(36)$ & $1.41(0.90-2.19)$ & 0.13 \\
\hline \multicolumn{5}{|l|}{ Private health insurance } \\
\hline Yes & $58(47)$ & $117 / 243(48)$ & ref. & \\
\hline No & $66(53)$ & $126 / 243(52)$ & $1.06(0.69-1.63)$ & 0.80 \\
\hline \multicolumn{5}{|l|}{ Clinical } \\
\hline \multicolumn{5}{|l|}{ Smoker } \\
\hline Previous/never smoking & $67(54)$ & $144(59)$ & ref. & \\
\hline Yes & $57(46)$ & $100(41)$ & $1.23(0.79-1.89)$ & 0.36 \\
\hline \multicolumn{5}{|l|}{ Hazardous drinker } \\
\hline No & $99(79)$ & $210(86)$ & ref. & \\
\hline Yes & $26(21)$ & $34(14)$ & $1.64(0.93-2.88)$ & 0.09 \\
\hline \multicolumn{5}{|l|}{ Comorbid chronic illness } \\
\hline No & $90(73)$ & $197(81)$ & ref. & \\
\hline Yes & $34(27)$ & 47 (19) & $1.58(0.95-2.63)$ & 0.08 \\
\hline \multicolumn{5}{|l|}{ Stroke subtype } \\
\hline Ischaemic & $104(84)$ & $204(84)$ & ref. & \\
\hline Haemorrhagic & $14(11)$ & $32(13)$ & $0.86(0.44-1.68)$ & 0.66 \\
\hline Unknown subtype & $6(5)$ & $5(2)$ & $2.35(0.70-7.89)$ & 0.17 \\
\hline
\end{tabular}


Table 1 (continued)

\begin{tabular}{llll}
$\begin{array}{l}\text { Insomnia } \\
\left(n=124^{*}\right)\end{array}$ & $\begin{array}{l}\text { No insomnia } \\
\left(n=244^{*}\right)\end{array}$ & OR $(95 \% \mathrm{CI})$ & $p$ value \\
\hline
\end{tabular}

\begin{tabular}{lccll}
\hline Thrombolysis & & & \\
$\quad$ No & $116(94)$ & $229 / 243(94)$ & ref. & \\
$\quad$ Yes & $8(6)$ & $14 / 243(6)$ & $1.13(0.46-2.77)$ & 0.79 \\
Cognitive status & & & & \\
$\quad$ Impaired & $16 / 121(13)$ & $46 / 232(20)$ & ref. & 0.12 \\
$\quad$ Competent & $105 / 121(87)$ & $186 / 232(80)$ & $1.62(0.88-3.01)$ & 0.02 \\
History of treated depression & $70(56)$ & $167(68)$ & ref. & \\
$\quad$ No & $54(44)$ & $77(32)$ & $1.67(1.07-2.61)$ & 0.0004 \\
$\quad$ Yes & $92 / 121(76)$ & $210 / 232(91)$ & ref. & \\
Depression & $29 / 121(24)$ & $22 / 232(9)$ & $3.01(1.64-5.52)$ & \\
$\quad$ No & $71 / 121(59)$ & $197 / 232(85)$ & ref. & $<0.0001$ \\
$\quad$ Yes & $50 / 121(41)$ & $35 / 232(15)$ & $3.96(2.38-6.60)$ & \\
Anxiety & No & & & \\
$\quad$ Yes & & & & \\
\hline
\end{tabular}

Data are displayed as $n(\%)$ or mean (SD). Odds ratios (OR) indicate the odds of having insomnia symptoms according to each baseline characteristic. CI, confidence interval. * Unless stated otherwise.

Table 2. Association of insomnia course with 12-month depression and anxiety symptoms

\begin{tabular}{|c|c|c|c|c|c|c|}
\hline & \multicolumn{6}{|c|}{ 12-month outcome, OR (95\% CI) } \\
\hline & \multicolumn{3}{|c|}{ Depression (HADS-D $\geq 8$ ) } & \multicolumn{3}{|c|}{ Anxiety (HADS-A $\geq 8$ ) } \\
\hline & Model 1 & Model 2 & Model 3 & Model 1 & Model 2 & Model 3 \\
\hline \multicolumn{7}{|l|}{ Pattern of insomnia } \\
\hline \multicolumn{7}{|l|}{ Never $(n=192)$} \\
\hline Chronic $(n=58)$ & $6.75(2.78-16.4)$ & $2.46(0.86-7.05)$ & $1.98(0.58-6.76)$ & $3.31(1.54-7.09)$ & $2.02(0.78-5.28)$ & $2.64(0.97-7.21)$ \\
\hline Recovery $(n=66)$ & $2.78(1.06-7.30)$ & $1.78(0.52-6.11)$ & $1.58(0.41-6.11)$ & $2.94(1.41-6.14)$ & $1.38(0.57-3.33)$ & $1.85(0.72-4.76)$ \\
\hline Late $(n=52)$ & $2.48(0.84-7.27)$ & $1.50(0.49-4.63)$ & $1.31(0.35-4.88)$ & $2.65(1.17-6.00)$ & $1.09(0.41-2.85)$ & $1.86(0.66-5.24)$ \\
\hline
\end{tabular}

OR, odds ratio; CI, confidence interval; HADS-D, Hospital Anxiety and Depression Scale depression subscale; HADS-A, Hospital Anxiety and Depression Scale anxiety subscale. Model 1 is adjusted for age and sex. Model 2 is adjusted for significant baseline psychological variables: depression, anxiety, prior treatment for psychological illness, and alcohol use. Model 3 is additionally adjusted for baseline disability/illness variables: WHODASII score and physical comorbidity.

Disability. "Chronic" insomnia over 6 months was independently associated with 12-month disability, after adjustment for demographic, psychiatric, and disability/illness variables (Table 3). Even after simultaneous adjustment for all measured potential confounders, this association remained (OR 2.39 for each increasing quartile of disability, 95\% CI 1.27-4.50). "Late" insomnia was associated with 12-month disability after adjustment for age and sex (OR 3.13, 95\% CI 1.77-5.52), but this association was attenuated in effect, and statistically to nonsignificance, after adjustment for psychiatric and disability/illness variables.

Return to Paid Work. Of the 271 who were working prior to their stroke, 202 (75\%) had returned to some form of work, either full- or part-time, by 12 months. 123/155 (79\%) of those without insomnia in the first 6 months had returned to work by a year. Those with "chronic" insomnia symptoms were 3 times less likely to return to paid work within the first 
Glozier et al.: The Course and Impact of Poststroke Insomnia in Stroke Survivors Aged 18 to 65 Years: Results from the Psychosocial Outcomes In StrokE (POISE) Study

Table 3. Association of insomnia course with 12 -month disability and return to paid work

\begin{tabular}{|c|c|c|c|}
\hline $\begin{array}{l}\text { 6-month characteristic } \\
\text { pattern of insomnia }\end{array}$ & $\begin{array}{l}\text { Model } 1 \\
\text { OR (95\% CI) }\end{array}$ & $\begin{array}{l}\text { Model } 2 \\
\text { OR }(95 \% \text { CI) }\end{array}$ & $\begin{array}{l}\text { Model } 3 \\
\text { OR ( } 95 \% \text { CI) }\end{array}$ \\
\hline \multicolumn{4}{|c|}{ Disability at 12 months $(n=368)$} \\
\hline Never $(n=192)$ & ref. & ref. & ref. \\
\hline Chronic $(n=58)$ & $3.60(2.07-6.25)$ & $2.47(1.36-4.51)$ & $2.39(1.27-4.50)$ \\
\hline Recovery $(n=66)$ & $3.13(1.77-5.52)$ & $2.12(1.15-3.93)$ & $1.51(0.76-3.00)$ \\
\hline Late $(n=52)$ & $1.76(1.05-2.95)$ & $1.21(0.69-2.11)$ & $1.16(0.63-2.15)$ \\
\hline \multicolumn{4}{|c|}{ Return to work by 12 months $(n=247)$} \\
\hline Never $(n=140)$ & ref. & ref. & ref. \\
\hline Chronic $(n=38)$ & $0.26(0.12-0.56)$ & $0.37(0.15-0.92)$ & $0.39(0.14-1.15)$ \\
\hline Recovery $(n=44)$ & $0.64(0.29-1.43)$ & $0.54(0.22-1.32)$ & $0.56(0.20-1.61)$ \\
\hline Late $(n=25)$ & $1.12(0.38-3.28)$ & $1.18(0.35-3.94)$ & $1.34(0.37-4.86)$ \\
\hline
\end{tabular}

OR, odds ratio; $\mathrm{CI}$, confidence interval. Modelling for disability using ordinal regression for increasing quartiles of WHODASII score. Modelling for return to work using logistic regression. Model 1 is adjusted for age and sex. Model 2 is adjusted for significant baseline psychological variables: depression, anxiety, prior treatment for psychological illness, and alcohol use. Model 3 is additionally adjusted for baseline disability/ illness variables: WHODASII score and physical comorbidity.

year after adjustment for demographic and psychiatric variables (OR 0.37, 95\% CI 0.15-0.92). The point estimate of the effect did not change after adjustment for disability/illness variables, although the association became marginally nonsignificant (OR 0.39, 95\% CI 0.121.15).

\section{Discussion}

\section{Main Findings}

This is the first study examining the course and impact of insomnia in younger stroke survivors and demonstrates that insomnia symptoms are common and are chronic in one sixth of patients over the first 6 months. Chronic insomnia in this period after stroke is associated with subsequent greater disability and a lower likelihood of returning to paid work. The associations with later depression and anxiety appear explained by comorbid psychological problems. Only half of those with chronic insomnia had returned to paid work at 12 months compared to nearly $80 \%$ of those without insomnia.

\section{Comparison with Other Studies}

Prevalence and Course. Insomnia syndrome is reported to be present in approximately $6-10 \%$ of the general working-age population and "insomnia symptoms without daytime fatigue" present in 13\% [26]. Only 2 previous studies have reported a prevalence of poststroke insomnia (symptoms with daytime consequences) suggesting rates of between 13 and $38 \%$ at 3 months in samples of older stroke survivors [2,3]. In this younger group, we found a relatively stable point prevalence of $30-37 \%$, indicating a prevalence 3 times greater than the working age population [26-28]. Of those with insomnia at both 1 and 6 months, the majority still had insomnia at 12 months, supporting many other population-based studies that those with chronic insomnia [27-29] are unlikely to subsequently recover.

Factors Associated with Poststroke Insomnia. A key finding was that insomnia did not appear to be associated with the range of psychosocial stressors commonly seen in popu- 
lation-based studies. Previous studies have suggested lower income [30], being divorced/ separated, having no private health insurance [31], and reporting high job stress [32] as associated with insomnia. It may be that the impact of stroke, or the recruitment from a hospital setting, may have diminished the relevance of these factors at this time for the participants.

Impact of Poststroke Insomnia. There are no other prospective longitudinal studies of poststroke insomnia with which to compare our results. Our data reveal some similarities with previous population-based studies with regard to the associations between insomnia and later depression/anxiety symptoms $[33,34]$. We found significantly higher baseline rates of depression and anxiety in those who reported insomnia, and that "chronic" insomnia was associated with depression and anxiety. These higher rates did not appear to be accounted for by comorbid physical disorders as the HADS [18] does not incorporate sleep symptoms arising from physical health conditions. Palomaki et al. [4] showed poststroke insomnia to be associated with depression severity, and there are cross-sectional links between insomnia, anxiety, psychotropic drug use [3], and depression [2]. This is unsurprising given that sleep symptoms are included in the diagnostic criteria for depression, an important feature of anxiety, and many psychotropics are prescribed for insomnia. Although the prospective associations of chronic insomnia with later psychiatric conditions were attenuated to nonsignificance after adjustment for confounding, nearly 75\% (39/54) of the chronic insomniacs had depression and/or anxiety at 12 months.

Economic Costs, Relationship with Disability, and Return to Paid Work. The health and economic costs attributed to insomnia are substantial [7]. A report by Deloitte [35] in 2010 estimated that the total health system cost of its symptoms are AUD 118.7 million/year [7, 36]. Other studies have suggested insomnia symptoms result in high indirect costs from loss of productivity [37].

In this study we demonstrated an association between chronic insomnia and subsequent disability. The association was strong even when potentially overadjusting by controlling for disability at baseline in addition to baseline psychological variables, age, and sex. This is despite this younger sample being less disabled than general stroke cohorts as the median score of the 32-item WHODAS 1 month after stroke was 8.2 at 12 months, compared to 18.5 at 12 months in a stroke survivors study with a higher average age [21].

A key objective measure of psychosocial disability is that of vocational function. One nationwide cohort study of working-age adults reported an association between insomnia, using the same measure as in this study, and increased risk of receiving a disability pension [38], independent of comorbid depression [8]. Approximately three quarters of all young stroke survivors return to paid work in Australasia $[12,13]$. The presence of chronic insomnia substantially reduced the likelihood of returning to paid work by 12 months, after adjusting for age, sex, and psychiatric comorbidity. Vocational services are rarely considered in this group as they are often cared for in geriatric wards or by geriatricians after the acute stroke unit stay; identifying insomnia and its effects may help these people return to the paid workforce. As unemployment is itself associated with poorer health [39] and mortality [40], a combination of these disabling outcomes following stroke has the potential for dramatic consequences for the patient, their family, and the wider community.

\section{Strengths and Limitations of the Study}

This study's strengths include a prospective design, a predetermined protocol, and high level of follow-up (84\%) [14]. Participants were consecutively recruited from a large stroke network with a diverse population and encompassing metropolitan and rural areas. As such, the results are likely to be widely generalizable for younger stroke survivors.

There are some limitations. There was a degree of attrition (one in ten). However those lost were less likely to be in paid work and reported higher levels of disability at baseline. As 
such, our results may be conservative as those not included were more likely to have poorer outcomes, i.e., the sample analysed was slightly healthier. The identification of insomnia symptoms does not exactly accord with the insomnia diagnosis in either the DSM5 or ICSD, but the definition matches many previous epidemiological studies' classification of insomnia [16]. We have no information on the existence of pure middle insomnia symptoms in this sample, but previous work has demonstrated that this is both uncommon and, in the absence of initial or late insomnia symptoms, highly unlikely to be associated with significant daytime impairment and therefore does not meet the consequences criteria for insomnia [41]. We did not ascertain prestroke insomnia as we do not claim, analogous to poststroke depression, that the stroke caused the insomnia. Only $4 \%$ of participants reported taking sleeping tablets at baseline, a level comparable to the general population [7]. The point is that this treatable comorbidity influences outcome after stroke. We did not specifically identify sleep-related breathing disorders such as obstructive sleep apnoea (OSA) in our study. However, using questions about snoring and stopping breathing from the KSQ suggested that although 161 (30\%) reported snoring "several times per week" or more frequently, only 26 (7\%) also reported that they were told they stopped breathing several times per week or more. As such, we believe that the contribution of OSA to the sleep of this younger group of stroke survivors is not significant, especially when compared to rates of up to $40 \%$ of older ( $>65$ years) stroke survivors meeting OSA screening criteria [6].

This study provides patients, families, and clinicians with the expected course and impact of insomnia in younger stroke survivors. We could find no studies identifying, screening, or intervening for poststroke insomnia, yet there are several evidence-based approaches to treating and screening for chronic insomnia [42]. Many of these, e.g., sleep hygiene, require little clinical input and there are newer internet-based modalities [43] that have proven efficacy and may not provide the same risk in a morbid population as some pharmacological interventions. We suggest that such an approach is worth evaluating to see if these observational findings could translate into insomnia-focused, adjunctive, interventions that improve poststroke outcomes and the associated personal and wider economic costs attributed to unemployment and health resource use.

\section{Acknowledgements}

We thank the participants in this study and the Stroke Services NSW, Agency for Clinical Innovation.

\section{Disclosure Statement}

The authors report no conflict of interest.

\section{Sources of Funding}

This study was funded by the National Health and Medical Research Council (NHMRC) of Australia (APP512429). During the completion of this work, Maree L. Hackett was in receipt of a National Heart Foundation Future Leader Fellowship \#100034. No funding bodies had a role in the conduct or reporting of this study. 


\section{Cereblovascular" Diseases}

\section{Author Contributions}

Conceived and designed the study: M.L.H., N.G., S.J. Analysed and interpreted the data: all. Wrote the paper: all. Performed the study: M.L.H., N.G., S.J. Critically reviewed and edited the manuscript: all.

\section{References}

1 American Academy of Sleep Medicine: International Classification of Sleep Disorders: Diagnostic and Coding Classification of Sleep Disorders 697 Manual, 2nd ed. Westchester, American Academy of Sleep Medicine, 2005.

-2 Chen YK, Lu JY, Mok VC, Ungvari GS, Chu WC, Wong KS, Tang WK: Clinical and radiologic correlates of insomnia symptoms in ischemic stroke patients. Int J Geriatr Psychiatry 2011;26:451-457.

-3 Leppavuori A, Pohjasvaara T, Vataja R, Kaste M, Erkinjuntti T: Insomnia in ischemic stroke patients. Cerebrovasc Dis 2002;14:90-97.

-4 Palomaki H, Berg A, Meririnne E, Kaste M, Lonnqvist R, Lehtihalmes M, Lonnqvist J: Complaints of poststroke insomnia and its treatment with mianserin. Cerebrovasc Dis 2003;15:56-62.

-5 Tang WK, Lu JY, Liang HJ, Chan TT, Mok V, Ungvari GS, Wong KS: Is insomnia associated with suicidality in stroke? Arch Phys Med Rehabil 2011;92:2025-2027.

-6 Ferre A, Ribo M, Rodriguez-Luna D, Romero 0, Sampol G, Molina CA, Alvarez-Sabin J: Strokes and their relationship with sleep and sleep disorders. Neurologia 2013;28:103-118.

7 Daley M, Morin CM, LeBlanc M, Gregoire JP, Savard J: The economic burden of insomnia: direct and indirect costs for individuals with insomnia syndrome, insomnia symptoms, and good sleepers. Sleep 2009;32:55-64.

-8 Overland S, Glozier N, Sivertsen B, Stewart R, Neckelmann D, Krokstad S, Mykletun A: A comparison of insomnia and depression as predictors of disability pension: the HUNT Study. Sleep 2008;31:875-880.

-9 Novak M, Mucsi I, Shapiro CM, Rethelyi J, Kopp MS: Increased utilization of health services by insomniacs - an epidemiological perspective. J Psychosom Res 2004;56:527-536.

-10 Sivertsen B, Pallesen S, Glozier N, Bjorvatn B, Salo P, Tell GS, Ursin R, Overland S: Midlife insomnia and subsequent mortality: the Hordaland health study. BMC Public Health 2014;14:720.

11 Daniel K, Wolfe CDA, Busch MA, McKevitt C: What are the social consequences of stroke for working-aged adults? A systematic review. Stroke 2009;40:E431-E440.

12 Hackett ML, Glozier N, Jan S, Lindley R: Returning to paid employment after stroke: the Psychosocial Outcomes In StrokE (POISE) cohort study. PloS One 2012;7:e41795.

-13 Glozier N, Hackett ML, Parag V, Anderson CS, Auckland Regional Community Stroke Study Group: The influence of psychiatric morbidity on return to paid work after stroke in younger adults: the Auckland Regional Community Stroke (ARCOS) Study, 2002 to 2003. Stroke 2008;39:1526-1532.

14 Hackett ML, Glozier N, Jan S, Lindley R: Psychosocial Outcomes in StrokE: the POISE observational stroke study protocol. BMC Neurol 2009;9:24.

15 Kecklund G, Åkerstedt T: The psychometric properties of the Karolinska Sleep Questionnaire. J Sleep Res 1992;1(suppl 1):113.

-16 Engstrøm M, Ødegård S, Sand T, Stovner L, Zwart J, Hagen K: The reliability of a new sleep screening questionnaire for large population-based studies: the third Nord-Trøndelag Health Study. Open Sleep J 2011;4:14-19.

-17 Edinger JD, Bonnet MH, Bootzin RR, Doghramji K, Dorsey CM, Espie CA, Jamieson AO, McCall WV, Morin CM, Stepanski EJ; American Academy of Sleep Medicine Work Group: Derivation of research diagnostic criteria for insomnia: report of an American Academy of Sleep Medicine Work Group. Sleep 2004;27:1567-1596.

$>18$ Zigmond AS, Snaith RP: The hospital anxiety and depression scale. Acta Psychiatr Scand 1983;67:361-370.

19 Bjelland I, Dahl AA, Haug TT, Neckelmann D: The validity of the Hospital Anxiety and Depression Scale. An updated literature review. J Psychosom Res 2002;52:69-77.

-20 Garin 0, Ayuso-Mateos JL, Almansa J, Nieto M, Chatterji S, Vilagut G, Alonso J, Cieza A, Svetskova O, Burger H, Racca V, Francescutti C, Vieta E, Kostanjsek N, Raggi A, Leonardi M, Ferrer M; MHADIE Consortium: Validation of the "World Health Organization Disability Assessment Schedule, WHODAS-2" in patients with chronic diseases. Health Qual Life Outcomes 2010;8:51.

21 Schlote A, Richter M, Wunderlich MT, Poppendick U, Moller C, Schwelm K, Wallesch CW: WHODAS II with people after stroke and their relatives. Disabil Rehabil 2009;31:855-864.

22 Bush K, Kivlahan DR, McDonell MB, Fihn SD, Bradley KA: The AUDIT alcohol consumption questions (AUDIT-C): an effective brief screening test for problem drinking. Ambulatory Care Quality Improvement Project (ACQUIP). Alcohol Use Disorders Identification Test. Arch Intern Med 1998;158:1789-1795.

23 de Jager CA, Budge MM, Clarke R: Utility of TICS-M for the assessment of cognitive function in older adults. Int J Geriatr Psychiatry 2003;18:318-324.

24 Australian Bureau of Statistics: 2006 Census. Australian Bureau of Statistics, 2006. 
Glozier et al.: The Course and Impact of Poststroke Insomnia in Stroke Survivors Aged 18 to 65 Years: Results from the Psychosocial Outcomes In StrokE (POISE) Study

25 Karasek R, Brisson C, Kawakami N, Houtman I, Bongers P, Amick B: The Job Content Questionnaire (JCQ): an instrument for internationally comparative assessments of psychosocial job characteristics. J Occup Health Psychol 1998;3:322-355.

26 Calem M, Bisla J, Begum A, Dewey M, Bebbington PE, Brugha T, Cooper C, Jenkins R, Lindesay J, McManus S, Meltzer H, Spiers N, Weich S, Stewart R: Increased prevalence of insomnia and changes in hypnotics use in England over 15 years: analysis of the 1993, 2000, and 2007 National Psychiatric Morbidity Surveys. Sleep 2012;35:377-384.

27 Morin CM, Belanger L, LeBlanc M, Ivers H, Savard J, Espie CA, Merette C, Baillargeon L, Gregoire JP: The natural history of insomnia: a population-based 3-year longitudinal study. Arch Intern Med 2009;169:447-453.

28 Suh S, Yang HC, Fairholme CP, Kim H, Manber R, Shin C: Who is at risk for having persistent insomnia symptoms? A longitudinal study in the general population in Korea. Sleep Med 2014;15:180-186.

29 Morin CM, Leblanc M, Ivers H, Belanger L, Merette C, Savard J, Jarrin DC: Monthly fluctuations of insomnia symptoms in a population-based sample. Sleep 2014;37:319-326.

-30 Talala KM, Martelin TP, Haukkala AH, Harkanen TT, Prattala RS: Socio-economic differences in self-reported insomnia and stress in Finland from 1979 to 2002: a population-based repeated cross-sectional survey. BMC Public Health 2012;12:650.

-31 Grandner MA, Petrov ME, Rattanaumpawan P, Jackson N, Platt A, Patel NP: Sleep symptoms, race/ethnicity, and socioeconomic position. J Clin Sleep Med 2013;9:897-905; 905A-905D.

-32 de Lange AH, Kompier MAJ, Taris TW, Geurts SAE, Beckers DGJ, Houtman ILD, Bongers PM: A hard day's night: a longitudinal study on the relationships among job demands and job control, sleep quality and fatigue. J Sleep Res 2009;18:374-383.

-33 Ford DE, Kamerow DB: Epidemiologic study of sleep disturbances and psychiatric disorders. An opportunity for prevention? JAMA 1989;262:1479-1484.

34 Batterham PJ, Glozier N, Christensen H: Sleep disturbance, personality and the onset of depression and anxiety: prospective cohort study. Aust N Z J Psychiatry 2012;46:1089-1098.

35 Deloitte: Re-Awakening Australia: The Economic Cost of Sleep Disorders in Australia. Sleep Health Foundation, 2011.

-36 Bin YS, Marshall NS, Glozier N: The burden of insomnia on individual function and healthcare consumption in Australia. Aust N Z J Public Health 2012;36:462-468.

-37 Kessler RC, Berglund PA, Coulouvrat C, Hajak G, Roth T, Shahly V, Shillington AC, Stephenson JJ, Walsh JK: Insomnia and the performance of US workers: results from the America insomnia survey. Sleep 2011;34: 1161-1171.

-38 Sivertsen B, Overland S, Neckelmann D, Glozier N, Krokstad S, Pallesen S, Nordhus IH, Bjorvatn B, Mykletun A: The long-term effect of insomnia on work disability: the HUNT-2 historical cohort study. Am J Epidemiol 2006;163:1018-1024.

-39 McKee-Ryan F, Song Z, Wanberg CR, Kinicki AJ: Psychological and physical well-being during unemployment: a meta-analytic study. J Appl Psychol 2005;90:53-76.

40 Clemens T, Popham F, Boyle P: What is the effect of unemployment on all-cause mortality? A cohort study using propensity score matching. Eur J Public Health 2015;25:115-121.

-41 Ohayon MM, Krystal A, Roehrs TA, Roth T, Vitiello MV: Using difficulty resuming sleep to define nocturnal awakenings. Sleep Med 2010;11:236-241.

42 Morin CM, Benca R: Chronic insomnia. Lancet 2012;379:1129-1141.

-43 Ritterband LM, Thorndike FP, Gonder-Frederick LA, Magee JC, Bailey ET, Saylor DK, Morin CM: Efficacy of an Internet-based behavioral intervention for adults with insomnia. Arch Gen Psychiatry 2009;66:692-698. 